\title{
Italian vowel production by Arabic speakers
}

\author{
Manuela Frontera ${ }^{1}$, Emanuela Paone ${ }^{2}$ \\ ${ }^{1}$ Department of Cultures, Education and Society, University of Calabria, Italy \\ ${ }^{2}$ Department of Humanities, University of Calabria, Italy \\ https://doi.org/10.36505/ExLing-2019/10/0022/000384
}

\begin{abstract}
This research wants to explore the production of Italian L2 vowels by native Arabic adult speakers living in Italy. It focuses, moreover, on the weight exerted by motivation on L2 speech. Accuracy in Italian L2 production is tested on two vowel oppositions, /i e/ and /o u/. First, with the purpose of judging the magnitude of spectral differences produced between /i e/ and /o u/, Euclidean distances between each opposition are calculated and compared, both for the Arabic speakers and an Italian control group. Then, spectral distances between Italian L1 and L2 B1-B0 and B3-B2 values are computed and examined in correlation with Arabic speakers' motivational indexes.
\end{abstract}

Key words: Unstressed vowels, Italian L2, Arabic L1, Motivation.

\section{Introduction}

Native-like phonological competence in the L2 is well known to be the most challenging achievement for new speakers, whose perceptual-productive processes are led and deeply filtered by their former language experience (Flege 1987; Best \& Tyler 2007). Moreover, matters of typological markedness and great "distances" between systems may slow down and even hinder the acquisition process, as well as the age factor (Eckmann 2008; Major 2014). However, extensive research studies have demonstrated the further fundamental weight of extra-linguistic/psychosocial factors, such as attitudes and motivation, on SLA (Moyer 2007), factors that will be explored through this study. Accuracy in Italian L2 production is here tested on two vowel oppositions, / $\mathrm{i}$ e/ and /o u/, in final unstressed context. These oppositions have been chosen because Arabic varieties' phonology lack of vowels /e/ and /o/ and, in addition, because all short vowels suffer from reduction processes when in open syllable and final position (Al-Ani 1970).

So, this research will test two main hypotheses: dealing with motivated subjects, it is argued that native Arabic speakers are able to accurately produce the aforementioned non-native vowel oppositions in Italian L2, but differences in motivational levels may trigger alterations in spectral distances from the native norm.

ExLing 2019: Proceedings of 10 $10^{\text {th }}$ International Conference of Experimental Linguistics, 25-27 September 2019, Lisbon, Portugal 


\section{Research methods Subjects}

The informants for this research are a control group of 6 native Italians (mean age $=37$ years) and 6 L1 Arabic speakers, 4 males and 2 females (mean age $=22,3$ years) from Egypt and Tunisia, learners of Italian L2, living in Italy since 1,8 years, on average. Each Arabic speaker is associated to a 0-to-3 linguistic motivation index extracted, together with other sociolinguistic information, through an ad hoc questionnaire by a previous research (Frontera \& Romito 2018).

\section{Speech material}

The subjects read a list of 60 words (15 words per vowel) where / i e o u/ are in $\mathrm{CV}$ final unstressed position, pronounced in a carrier phrase, "Dico $\mathrm{X}$ rapidamente/con calma" (I say X rapidly/with calm), where $\mathrm{X}$ is one of the target words elicited in random order. Recordings take place in a silent room, using an Edirol UA-25 audio device, an Audio Technica AT4033 condenser microphone, with a sample frequency of $44.100 \mathrm{~Hz}, 16 \mathrm{bit}$, mono.

\section{Analyses}

All the target vowels are labelled starting from the second positive peak up to the last clearly visible pulse. Vowel frequency values (F0, F1, F2, F3), in their mid-point, and durations in $m s$ are extracted and manually corrected in Praat, then formant values are converted to Barks. Given this data, for each vowel, global frequencies, duration means, and standard deviations are observed and compared between the two groups. With the purpose of judging the magnitude of spectral differences that subjects produced between $/ \mathrm{i}$ e/ and $/ \mathrm{o} \mathrm{u} /$, Euclidean distances are calculated between each opposition, both for the Arabic speakers and the control group. Consequently, Italian L2 spectral distances are compared to the native Italian norm. Hence, new Euclidean distances between Italian L1 and L2 B1-B0 and B3-B2 values are computed, and examined in correlation with Arabic speakers' motivational indexes.

\section{Results}

Due to preliminary ANOVAs which showed no significant differences in vowel highness and frontness/backness related to speakers' gender, and former Arabic dialectal varieties (Egyptian vs. Tunisian), data from male and female speakers were combined, as well as those obtained by all Italian L2 speakers. 

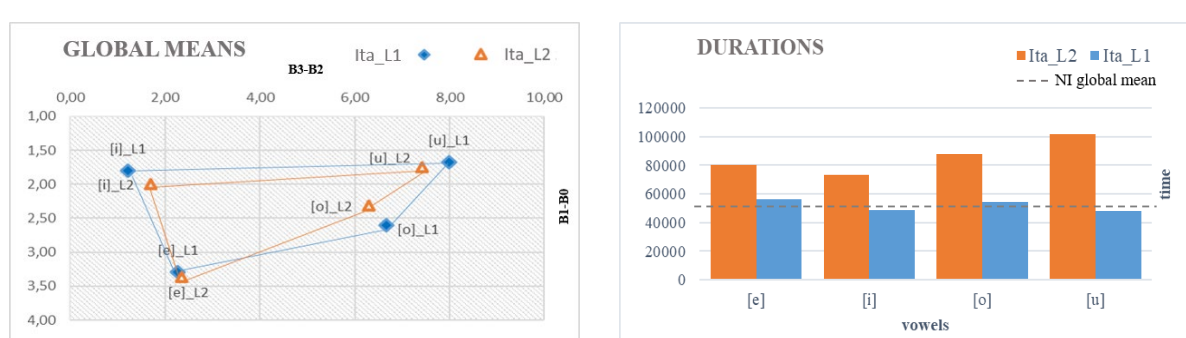

Figure 1 (on the left), Figure 2 (on the right). Global spectral means and durations of Italian /i e o u/ vowels produced by 6 Arabic speakers and a native Italian control group.

The ANOVA on Italian L1/L2 B1-B0 and B3-B2 values for the four vowels reveals significant differences between the two groups. More in depth comparisons $(t$-tests) show divergences in $/ \mathrm{i} /$ highness $(\mathrm{p}<.01)$ and frontness $(\mathrm{p}<.001)$, while /o/ and /u/ only seem to be, respectively, significantly higher $(\mathrm{p}<.001)$ and slightly lower $(\mathrm{p}<.05)$ when pronounced by the Arabic group (see Figure 1). Italian L1 vowel durations (in Figure 2) are systematically shorter in a significant way.

Repeated measures analyses carried out on the Euclidean distances obtained between /i/-/e/ and /u/-/o/ (see Table 1) confirm a significant variability between and within subjects, as regards the oppositions examined: a series of $t$ tests specifies that vowels / i e/ are significantly less distant in Italian L2 respect to the control group $[\mathrm{t}(185)=1,97, \mathrm{p}<.01]$.

Table 1. Mean spectral distances between /i/-/e/ and /u/-/o/ as produced by the Arabic speakers (Italian L2) and the control group (Italian L1).

\begin{tabular}{l|ll}
\hline \hline & $/ \mathrm{i} /-/ \mathrm{e} /$ & $/ \mathrm{u} /-/ \mathrm{o} /$ \\
\hline Italian L1 & $2,02(0,36)$ & $1,65(0,73)$ \\
Italian L2 & $1,74(0,45)$ & $1,60(0,82)$ \\
\hline \hline
\end{tabular}

According to the Euclidean distances (ED) calculated between Italian L2 and Italian L1 /i e o u/, back vowels seem to be the most distant from the native norm indeed $[/ \mathrm{u} / \mathrm{M}=1,56$ (S.D.=0,98); $/ \mathrm{o} / \mathrm{M}=1,33$ (S.D.=0,75)] and their distance values diverge in a significant way $(\mathrm{p}<.001$ and $\mathrm{p}<.05$, respectively) from those computed for front vowels /i/ and /e/ [/i/ $\mathrm{M}=1,01$ (S.D. 0,6); /e/ $\mathrm{M}=1,04$ (S.D. 0,6)]. Then, an ANCOVA is carried out to measure the impact exerted by motivation on vowels' EDs from the native models, using the Age of Arrival in Italy of each speaker, Lengths Of Residence and self-assessed levels of competence in Italian L2 as covariates. Motivational indexes (MIs) are scalar values on a continuum from 0 to 3 where the min. and max. measures are 1,88 and 2,59. Albeit the lowest index corresponds to the highest mean ED $(\mathrm{M}=1,75$, s.d. 1,23), the lowest $\mathrm{ED}(\mathrm{M}=0,98$, s.d. 0,6$)$ is related to the MI 1,98, 
far from the max. $(M=1,26$, s.d. 0,6). If vowels confirm their strongest impact on variation, MIs trigger a slight significant variation of $\mathrm{ED}$ values (within subjects) $(\mathrm{p}<.01$, eta squared 0,03$)$ : in order to observe the "direction" and strength of this effect, L2-to-L1 EDs, for each vowel, are finally correlated to Arabic speakers' MIs, by computing Pearson's correlation coefficients. Despite the resulting negative correlation between MI and distance scores, for /i/, /o/ and $/ \mathrm{u} /$, the obtained data is not statistically significant ( $\mathrm{p}$ values are always $>.05)$.

\section{Conclusions}

According to the present results, the Arabic speakers have shown themselves able to differentiate the tested oppositions: their spectral values are somehow centralized respect to the L1 model, but vowels seem to be properly discriminated by the investigated group. Though, front vowels are produced as consistently less distant from each other and, generally speaking, all vowel duration times almost double those of NIs: this could be interpreted as a sort of strategy of target achievement, to be better explored through further specific analyses, based on speech rate divergences. The motivational factor has not revealed a powerful correlation with better performances, nevertheless, in order to strengthen the present results, future analyses will be addressed to a broader number of non-native speakers and a wider range of MIs, including data from non or less motivated subjects.

\section{References}

Al-Ani, S. 1970. Arabic Phonology. Paris: The Hague.

Best, C. T. \& Tyler, M. D. 2007. Nonnative and second-language speech perception: Commonalities and complementarities. In Bohn, O.-S. and Munro M. (eds.) 2007. Language Experience in Second Language Speech Learning. In honor of Jim Flege, 13-34. Amsterdam: John Benjamins.

Eckman, F. R. 2008. Typological markedness and second language phonology. In Hansen Edwards, J. G. and Zampini, M. L. (eds.) 2008. Phonology and Second Language Acquisition, 95-115. Amsterdam-Philadelphia: John Benjamins.

Flege, J. 1987. The production of "new" and "similar" phones in a foreign language: Evidence for the effect of equivalence classification. Journal of Phonetics 15, 47-65.

Frontera, M. \& Romito, L. 2018. "Vorrei perdere il mio accento straniero": indici motivazionali di migranti culturali in Italia, Quaderni del Dipartimento di Linguistica, 26 (in press).

Major, R. C. 2014. Foreign accent: The ontogeny and phylogeny of second language phonology. New York and London: Routledge

Moyer, A. 2007. Do Language Attitudes Determine Accent? A Study of Bilinguals in USA. Journal of Multilingual and Multicultural Development 28, 502-518. 